\title{
Undergraduate exposure to urology: impact of the distributed model of medical education in British Columbia
}

\author{
Nathan A. Hoag, MD; Reza Hamidizadeh, MD; Andrew E. MacNeily, MD, FRCSC
}

See related article on page 26 .

Cite as: Can Urol Assoc J 2013;7:20-5. hittp://10.5489/cuaj.10101. Epub 2011 May 1.

\section{Abstract}

Background: With the increased development of distributed sites for medical education across Canada, it is imperative we ensure that the quality of education is comparable between the different campuses. Our objective was to assess medical student experience and comfort with common urologic clinical encounters and to determine whether any differences exist between the distributed education sites at the University of British Columbia (UBC).

Methods: Questionnaires assessing urologic education were delivered simultaneously to all final-year UBC medical students attending campuses in Vancouver, Victoria and Prince George. Results were analyzed using descriptive statistics.

Results: Overall, $55.8 \%$ of students felt their exposure to urology was adequate in the medical curriculum; learners in the Northern Program (Prince George) ranked their clinical and didactic experiences significantly higher. Areas requiring improvement include teaching of the male genitourinary exam, digital rectal exam and sexual history, in which learners rated teaching "good/outstanding" in only $18.2 \%, 47.7 \%$ and $43.2 \%$ of cases, respectively. Overall, students were most comfortable with the following clinical encounters: urinary tract infection, nephrolithiasis, benign prostatic hyperplasia, hematuria, incontinence and prostate cancer. Few differences in student experience or comfort were noted related to campus site, gender or urology clerkship exposure.

Conclusion: A significant minority of learners perceived that they had inadequate exposure to urology in the undergraduate curriculum. Experience in urology was comparable across the distributed sites and was congruent with teaching objectives. Students were comfortable with the clinical scenarios deemed most important in the literature. Learners in the Northern Program were significantly more satisfied with their urologic teaching, which potentially highlights the advantages of learning in a smaller academic setting.

\section{Résumé}

Contexte : En raison de l'augmentation du nombre de sites " satellites » de formation médicale au Canada, il est impératif de s'assurer que la qualité de l'éducation est comparable d'un campus à l'autre. Notre objectif était d'évaluer l'expérience des étudiants en médecine et leur niveau d'aise avec les cas courants rencontrés en urologie et de déterminer s'il existe des différences entre les différents sites de formation de l'Université de la ColombieBritannique (UCB).

Méthodologie : Des questionnaires évaluant la formation en urologie ont été livrés simultanément à tous les étudiants de I'UCB en dernière année de médecine des campus de Vancouver, Victoria et Prince George. Les résultats ont été analysés à I'aide de statistiques descriptives.

Résultats : Dans l'ensemble, 55,8\% des étudiants croyaient que leur expérience en urologie était adéquate dans le cadre du cursus médical. Les étudiants du programme du nord (Prince George) ont accordé des cotes significativement plus élevées à leur expérience clinique et didactique. Les domaines où une amélioration était souhaitée incluaient l'enseignement de l'examen génito-urinaire chez I'homme, du toucher rectal et de la vérification des antécédents sexuels, où les répondants ont évalué l'enseignement comme étant "bon/excellent » dans seulement 18,2\%, 47,7 \% et 43,2\% des cas, respectivement. Règle générale, les étudiants étaient le plus à I'aise avec les cas cliniques suivants : infection des voies urinaires, néphrolithiase, hyperplasie bénigne de la prostate, hématurie, incontinence et cancer de la prostate. Peu de différences ont été notées dans l'expérience ou le niveau d'aise des étudiants selon le campus, le sexe ou le fait d'avoir fait un stage clinique en urologie. Conclusion : Une minorité significative d'étudiants percevaient que leur expérience en urologie dans le cadre du curriculum de premier cycle était insuffisante. L'expérience en urologie était comparable dans les sites "satellites » et cohérente avec les objectifs d'apprentissage. Les étudiants étaient à l'aise avec les scénarios cliniques jugés les plus importants selon la littérature. Les étudiants du programme du nord étaient significativement plus satisfaits de l'enseignement urologique reçu, ce qui fait peut-être ressortir l'avantage d'étudier sur un plus petit campus. 


\section{Introduction}

Medical student exposure and experience in urology differs between institutions, which is likely a function of the varied structure of clerkship and pre-clerkship curricula. ${ }^{1}$ While no comprehensive study comparing urology-specific education between Canadian medical schools has been conducted, it is probable that there is variability in the content and delivery of such education.

According to the 2009 Canadian Residency Matching Service statistics, $32.5 \%$ of Canadian medical school graduates entered family practice residency, nationally. ${ }^{2}$ With an aging patient population, the frequency with which these graduates will encounter common urologic problems in the primary care setting will increase. A recent study demonstrated the projected increase in men with lower urinary tract symptoms in Canada, and concluded that an increasing proportion of the management burden may rest with primary care physicians. ${ }^{3}$ This highlights the importance of effective urologic education, both didactic and clinical, during the medical undergraduate years.

Despite this demographic imperative, surveys have demonstrated a decline in formal urologic education among medical students in the United States. ${ }^{4}$ If these findings are extrapolated to Canadian medical schools, concern arises whether graduating students are adequately prepared for common urologic clinical encounters when they enter practice. It should be noted, however, that there has been no evidence to suggest that this decline in formal urologic education has had a detrimental impact on care delivered by primary care physicians in practice to date. ${ }^{4}$

A distributed education model has been employed in the United States and Australia, where students study at sites away from the main institution, but follow a common curriculum. ${ }^{5}$ This model is also of interest to Canadian medical educators due not just to the novelty of delivering education in this manner, but also because many medical schools in Canada are implementing this model. These universities include: The University of British Columbia (UBC), Université de Montréal, Northern Ontario School of Medicine, Université de Sherbrooke, University of Toronto, Dalhousie University and the University of Western Ontario. ${ }^{5}$

UBC was the first medical school in Canada to adopt and implement the distributed model of undergraduate medical education. This involved a collaborative effort between the University of Northern British Columbia (Northern Medical Program [NMP], Prince George, BC) and the University of Victoria (Island Medical Program [IMP], Victoria, BC), with the first cohort of students beginning studies in 2004. Students in the distributed sites follow a common curriculum, which is delivered primarily by videoconferencing technology, a medium that has been shown to be an effective and accepted method of delivering a comparable educational experience. ${ }^{6,7}$ To date, student performance on standardized examinations has been comparable between the distributed sites both at UBC and at other institutions in the country. ${ }^{6,8}$

\section{Methods}

We surveyed final-year medical students at UBC to determine their exposure to common urologic conditions and gauge their comfort in dealing with these problems at a single institution. We also assessed whether the distributed model of education has had a significant impact on urological education in the undergraduate medical curriculum.

A questionnaire was designed based on a previously administered, validated urology curriculum surveys, ${ }^{1}$ including findings from M. Melnyk, L. Guerra and M.P. Leonard (unpublished data, 2010) and in accordance with recommendations on survey design. ${ }^{9}$ The questionnaire was then reviewed and edited by a urologist with expertise in medical education (Appendix 1).

Respondent demographics, including gender and education site within the distributed program, were captured. Questions were grouped to assess student experience, clinical teaching and comfort with common urologic scenarios using the Likert scale, and by self-reporting the frequency of these encounters. We also used binary (yes/no) questions to gauge student experience in urology and their interest in the specialty as a career choice.

Surveys were administered in person to fourth year UBC medical students concurrently at the Vancouver, Prince George, and Victoria sites in January 2010.

The responses were tabulated and SPSS version 16.0 (IBM Corporation, Somers, NY) was used to compute descriptive statistics. Chi-square testing was employed to assess relationships between medical student demographics and responses.

\section{Results}

The overall response rate was $88 / 216(40.7 \%)$, with sitespecific response rates for the VFMP, IMP and NMP of $56 / 170(32.9 \%), 17 / 23(73.9 \%)$ and $13 / 23(56.5 \%)$, respectively. Three students did not specify an educational site. Respondents included $42.7 \%$ males and $57.3 \%$ females.

We documented the mean student comfort with urologic clinical encounters and investigations/procedures (Table 1) (Table 2). We also tallied the self-reported experiences with these investigations (Fig. 1) (Fig. 2).

Of all those surveyed, $41.2 \%$ reported rotating through urology during their surgery clerkship, with significantly more students in the NMP doing urology during clerkship $92.3 \%(12 / 13)(p=0)$. Of the respondents, $11.5 \%$ of students completed a fourth year elective in urology, while $5.9 \%$ of respondents applied to urology as a discipline in the CaRMS 
Hoag et al.

\begin{tabular}{lc}
\hline $\begin{array}{l}\text { Table 1. Mean student self-reported comfort with common } \\
\text { urology-specific clinical encounters }\end{array}$ \\
\hline Clinical scenario & Mean response (out of 5) \\
\hline Adult urinary tract infection & 4.05 \\
Nephrolithiasis & 3.90 \\
Symptoms of benign prostatic & 3.77 \\
hyperplasia & \\
Hematuria & 3.58 \\
Urinary incontinence & 3.30 \\
Prostate cancer & 3.29 \\
Pediatric urinary tract infection & 3.27 \\
Acute scrotal pain & 3.20 \\
Scrotal masses & 3.06 \\
Erectile dysfunction & 2.94 \\
Epididimytis & 2.90 \\
Prostatitis & 2.83 \\
Male factor subfertility & 2.26 \\
\hline
\end{tabular}

match, with no significant associations between education site and gender.

With respect to using online case-based learning modules, $31.4 \%$ of students reported utilizing such resources developed at UBC. Female students were significantly less likely to employ this method of learning $(p=0.01)$. Overall, $55.8 \%$ of students felt that exposure to urology in the medical curriculum was adequate; with $100 \%$ of students in the NMP feeling it was adequate $(p<0.01)$.

Of the respondents, $39.5 \%$ felt that scheduled didactic urology teaching during surgery clerkship was good/outstanding, while $34.9 \%$ rated the quality of clinical teaching in urology as good/outstanding. For both questions, students in the NMP were more likely to rate teaching favourably ( $p$ $=0.02, p \leq 0.01$, respectively).

When asked about specific teaching topics, $47.7 \%$ of students felt that teaching of the digital rectal examination (DRE) was good/outstanding, $18.2 \%$ felt that teaching of the male genitourinary exam was good/outstanding and $43.2 \%$ felt that teaching of sexual history was good/outstanding. Students in the NMP reported significantly higher quality teaching on DRE and male genitourinary examination $(p<0.01)$.

Other specific significant differences noted between the educational sites include NMP students being more comfortable than students at other sites with cystoscopy $(p=0.03)$, and ultrasound bladder scanning $(p=0.02)$. Students at both the NMP and IMP had more experience with vasectomy $(p=0.01, p<0.01$, respectively). Overall, female students were more comfortable dealing with adult urinary tract infections than their male counterparts $(p<0.01)$.

\section{Discussion}

The urology objectives in the UBC curriculum emphasize evaluation of hematuria with a focus on urolithiasis, trauma

\begin{tabular}{lc}
$\begin{array}{l}\text { Table 2. Mean student self-reported comfort in performing/ } \\
\text { interpreting common urology-specific investigations and } \\
\text { procedures }\end{array}$ \\
\hline Investigation/procedure & Mean response (out of 5) \\
\hline Urinalysis & 4.13 \\
Digital rectal examination & 3.88 \\
Sexual history & 3.36 \\
Urinary catheterization (male) & 3.30 \\
Urinary catheterization (female) & 3.30 \\
Computed tomography scan & 3.14 \\
(kidney, ureter, bladder) & \\
Male genitourinary exam & 2.95 \\
Renal ultrasound & 2.62 \\
Semen analysis & 2.31 \\
Urodynamics & 1.99 \\
Cystoscopy & 1.69 \\
Vasectomy & 1.43 \\
Circumcision & 1.23 \\
\hline
\end{tabular}

and malignancy. It also places importance on voiding dysfunction, benign prostatic hyperplasia $(\mathrm{BPH})$, prostate cancer and incontinence. Students are also expected to have knowledge in and experience with pediatric urology, erectile dysfunction and scrotal masses. When comparing mean student comfort with these specific encounters, in general, students report they are comfortable dealing with common

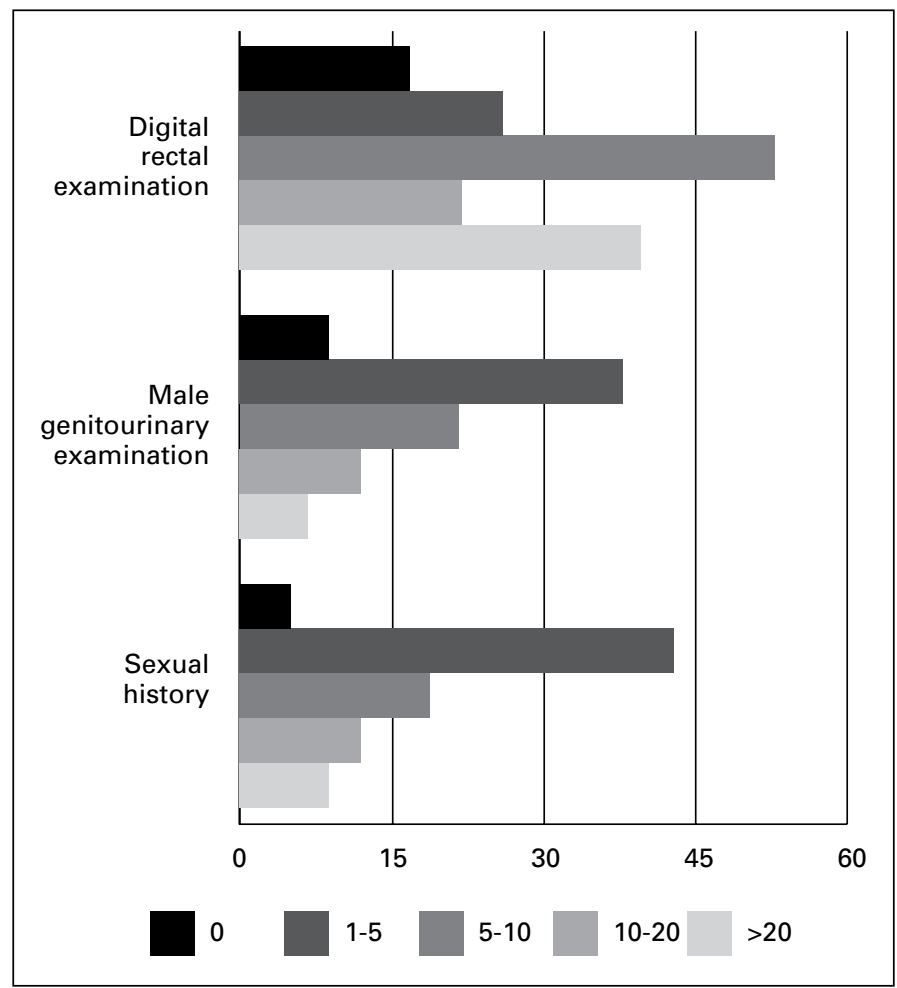

Fig. 1. Self-reported overall student experience in urology-specific history and physical examination (number performed). 


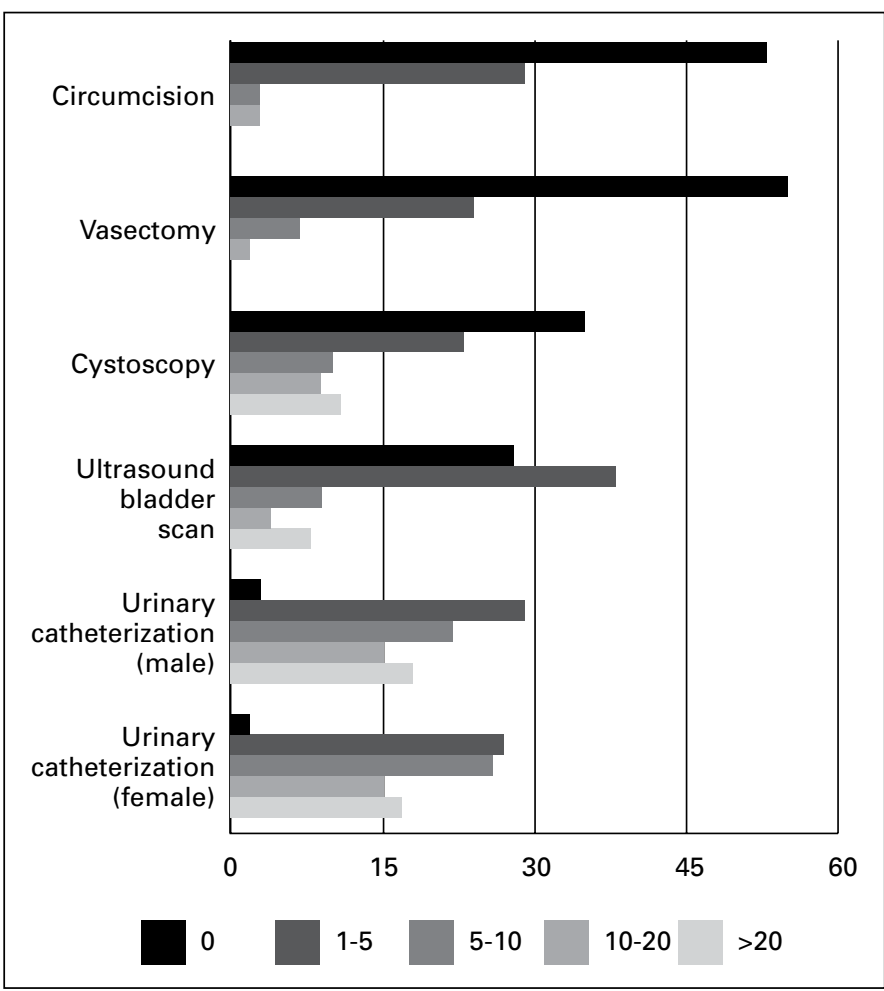

Fig. 2. Self-reported overall student experience in urology-specific investigations and procedures (number observed/performed).

urologic encounters upon graduation, although there is still room for improvement.

Kerfoot and Turek ${ }^{10}$ conducted a stakeholder's survey to determine the most important curricular topics in urology. The top 6 topics were: urinary stone disease, hematuria, adult urinary tract infections, $\mathrm{BPH}$, incontinence and prostate cancer. These 6 topics are the same 6 clinical encounters which students felt most comfortable with, indicating that both the UBC curriculum and distributed programs are achieving the desired outcomes.

The differences seen with NMP and IMP students being more comfortable/experienced with cystoscopy, vasectomy and ultrasound bladder scanning is possibly a function of these students spending more time in the urology clinic where these procedures are performed more frequently.

Students in the NMP were significantly more satisfied with their urology-specific teaching. Teaching there is more often delivered in smaller groups and in informal settings. When combined with dedicated faculty in these types of distributed sites, the educational experiences of students can be equal or superior to those students in the main institution. However, given the small sample size in the distributed sites, some of the differences observed could have been attributable to one or two excellent urology preceptors at a particular site. This could account for some of the increased satisfaction with urology education in the NMP.
Limitations to this study include reliance on self-reported comfort and experience by students which can result in disclosure bias. The students who returned surveys were those in attendance on the day of survey distribution, and it is not known for certain if the results can be extrapolated to the class as a whole. It would also have been ideal to review both the formal and informal curriculum between the distributed sites to identify any inter-site differences, as well as comparing this to urology curricula at medical schools across Canada.

Only $31.4 \%$ of students used locally developed online case based educational modules. This represents an area where expanded participation across the distributed sites could potentially equalize the urology experience for all undergraduates.

There appears to be room for improvement on teaching of the male genitourinary exam, DRE and sexual history; respondents modestly rated teaching as "good/outstanding" $18.2 \%, 47.7 \%$, and $43.2 \%$, respectively for the 3 sites. Student feedback on the most effective teaching methods may be helpful, and evaluation of the clinical skills teaching modules for these subjects would be appropriate.

Given that all medical school curricula are designed with the same principles and goals, which include providing students with sufficient knowledge and skills to manage common urologic conditions in the primary care setting, we feel that our findings could be generalizable to medical schools across Canada. Although the results of this study are specific to urologic education at one institution, they may be useful to other academic centres as they introduce curricula into distributed learning models. With more medical students educated in Canada under this model, information about knowledge gaps and where to focus continuing medical education is requisite.

\section{Conclusions}

With continuing medical school expansions in Canada, a greater proportion of urologic education will be delivered in a distributed education model. This study is an initial indication that this model can be successful in delivering urologic undergraduate education in an effective and equitable fashion across distributed sites.

Department of Urologic Sciences, University of British Columbia, Vancouver, BC

Competing interests: None declared.

This paper has been peer-reviewed. 
Hoag et al.

\section{Appendix 1.}

Dear 4th year UBC medical students:

We are conducting a survey of final year medical students at the University of British Columbia to evaluate the adequacy of urology teaching and students experiences under the distributed education model.

We hope to determine how the distribution of medical education has impacted students learning opportunities, clinical experience, and attitudes towards urology and the surgical specialties. We also hope to determine how comfortable graduating medical students are when dealing with common urological clinical encounters and procedures.

If you decide to participate, the questionnaire will require 5-10 minutes of your time. We would greatly appreciate your participation, as this information will be helpful in assessing the strengths and weaknesses of the current curriculum and to identify how clinical and didactic teaching could be improved for future years. There are no known risks to participating.

Subject identities will be kept confidential. No personal information will be collected that could identify subjects. Data will be stored on a secured computer.

If the questionnaire is completed, it will be assumed that consent has been given.

Your participation in this study is entirely voluntary and you may refuse to participate or withdraw from the study at any time without jeopardy to your education.

Please feel free to contact the principal investigator or co-investigator should you have any questions or concerns.

Which program are you in? (circle one) VFMP IMP NMP

Gender (circle one) $\quad$ M

Please rate your comfort in accurately performing the following procedures/history. Digital Rectal Examination

Male Genitourinary Examination

Sexual History

\begin{tabular}{ccccc}
\multicolumn{2}{c}{ Least Comfortable } & \multicolumn{2}{c}{ Most Comfortable } \\
1 & 2 & 3 & 4 & 5 \\
1 & 2 & 3 & 4 & 5 \\
1 & 2 & 3 & 4 & 5 \\
\hline
\end{tabular}

How many of the following have you performed?

Digital Rectal Examination

Male Genitourinary Examination

$\begin{array}{llll}0 & 1-5 & 5-10 & 10-20\end{array}$

Sexual History

$0 \quad 1-5$

5-10

$10-20$

$>20$

How would you rate the clinical teaching you received for each of the following?

Digital Rectal Examination

Male Genitourinary Examination

Sexual History

Please rate your comfort interpreting the following investigations:

Urinalysis

Semen analysis

Urodynamic Studies

CT KUB

Renal ultrasound

Please rate your comfort in performing the following procedures:

Circumcision

Vasectomy

Cystoscopy

Ultrasound Bladder scan

Urinary Catheterization (Male)

Urinary Catheterization (Female)

\section{References}

1. Teichman JMH, Monga M, Littlefield JH. Third year medical student attitudes toward learning urology. J Urol 2001;165:538-41.

2. Canadian Resident Matching Service. hittp://www.carms.ca. Accessed April 11, 2011.

3. Rawson NSB, Saad F. The aging male population and medical care for benign prostatic hyperplasia in Canada. Can Urol Assoc J 2010:4:123-7.

4. Kerfoot BP, Masser BA, DeWolf WC. The continued decline of formal urological education of medical students in the United States: Does it matter? J Urol 2006;175:2243-8.

5. Kondro W. Eleven satellite campuses enter orbit of Canadian medical education. CMAJ 2006;176:70.

6. Bates J. Medical school expansion in BC. BCMJ 2008;50:368-70.

7. Bianchi F, Stobbe K, Eva K. Comparing academic performance of medical students in distributed learning sites: The McMaster experience. Med Teach 2008;30:67-71.

8. Cook A, Pippi Salle JL, Reid J, et al. Prospective evaluation of remote, interactive videoconferencing to enhance urology resident education: The genitourinary teleteaching initiative. J Urol 2005;174:1958-60. 


\begin{tabular}{|c|c|c|c|c|c|}
\hline \multicolumn{6}{|l|}{ How many of the following procedures have you performed/observed? } \\
\hline Circumcision & 0 & $1-5$ & $5-10$ & $10-20$ & $>20$ \\
\hline Vasectomy & 0 & $1-5$ & $5-10$ & $10-20$ & $>20$ \\
\hline Cystoscopy & 0 & $1-5$ & $5-10$ & $10-20$ & $>20$ \\
\hline Ultrasound Bladder scan & 0 & $1-5$ & $5-10$ & $10-20$ & $>20$ \\
\hline Urinary Catheterization (Male) & 0 & $1-5$ & $5-10$ & $10-20$ & $>20$ \\
\hline Urinary Catheterization (Female) & 0 & $1-5$ & $5-10$ & $10-20$ & $>20$ \\
\hline $\begin{array}{l}\text { Please rate your comfort with your approach to dealing with the following clinical } \\
\text { scenarios: }\end{array}$ & \multicolumn{3}{|c|}{ Least Comfortable } & \multicolumn{2}{|c|}{ Most Comfortable } \\
\hline Hematuria & 1 & 2 & 3 & 4 & 5 \\
\hline Adult Urinary Tract Infection & 1 & 2 & 3 & 4 & 5 \\
\hline Symptoms of BPH & 1 & 2 & 3 & 4 & 5 \\
\hline Epididymitis & 1 & 2 & 3 & 4 & 5 \\
\hline Prostatitis & 1 & 2 & 3 & 4 & 5 \\
\hline Erectile Dysfunction & 1 & 2 & 3 & 4 & 5 \\
\hline Urinary Incontinence & 1 & 2 & 3 & 4 & 5 \\
\hline Nephrolithiasis & 1 & 2 & 3 & 4 & 5 \\
\hline Prostate Cancer & 1 & 2 & 3 & 4 & 5 \\
\hline Pediatric Urinary Tract Infection & 1 & 2 & 3 & 4 & 5 \\
\hline Acute Scrotal pain & 1 & 2 & 3 & 4 & 5 \\
\hline Scrotal Masses & 1 & 2 & 3 & 4 & 5 \\
\hline Male Factor Subfertility & 1 & 2 & 3 & 4 & 5 \\
\hline \multirow[t]{2}{*}{$\begin{array}{l}\text { How would you rate the quality of urologic teaching during surgery clerkship academic } \\
\text { half day sessions? }\end{array}$} & Poor & & & \multicolumn{2}{|c|}{ Outstanding } \\
\hline & 1 & 2 & 3 & 4 & 5 \\
\hline \multirow[t]{2}{*}{ How would you rate the quality of clinical teaching in urology overall? } & Poor & & & \multicolumn{2}{|c|}{ Outstanding } \\
\hline & 1 & 2 & 3 & 4 & 5 \\
\hline Did you apply to one or more urology programs via the CaRMS match? & Yes & No & & & \\
\hline Did you rotate through urology as a surgery clerkship selective in 3rd year? & Yes & No & & & \\
\hline Did you or will you complete a 4th year urology elective? & Yes & No & & & \\
\hline $\begin{array}{l}\text { Did you use online case-based modules for learning about urological diseases and } \\
\text { management? }\end{array}$ & Yes & No & & & \\
\hline Was exposure to urology in the medical curriculum adequate? & Yes & No & & & \\
\hline
\end{tabular}

9. McColl E, Jaoby A, Thomas L, et al. Design and use of questionnaires: A review of best practice applicable to surveys of health staff and patients. Health Technol Assess 2001;5:1-256.

10. Kerfoot BP, Turek PJ. What every graduating medical student should know about urology: The stakeholder viewpoint. Urology 2008;71:549-53.
Correspondence: Dr. Nathan A. Hoag, Department of Urologic Sciences, University of British Columbia, Gordon \& Leslie Diamond Health Care Centre, Level 6, 2775 Laurel St., Vancouver, BC V5Z 1M9; natman@interchange.ubc.ca 